\title{
Aplicação de ácido giberélico (GA3) e anatomia da epiderme foliar visando à detecção de variantes somaclonais de bananeira Musa sp. Colla cv. Prata-anã (Musaceae) ${ }^{1}$
}

\author{
Janaína de Oliveira Costa Silva², Guilherme Araújo Lacerda², Evaristo Mauro de Castro ${ }^{2,4}$, Antonio Chalfun-Júnior², \\ Luciano Vilela Paiva ${ }^{3}$ e Cynthia de Oliveira ${ }^{2}$
}

Recebido em 12/07/2008. Aceito em 12/03/2009

RESUMO - (Aplicação de ácido giberélico $\left(\mathrm{GA}_{3}\right)$ e anatomia foliar visando à detecção de variantes somaclonais de bananeira Musa sp. Colla cv. Prata-anã (Musaceae)). A micropropagação de indivíduos do gênero Musa vem sendo aplicada em larga escala para obtenção de mudas de qualidade fitossanitária. O cultivo in vitro pode levar a ocorrência de variação somaclonal que pode acarretar em prejuízos aos produtores. Atualmente, a diferenciação das plantas variantes somaclonais é possível somente quando as mesmas encontram-se em condições de campo, mediante crescimento exagerado, conhecido como gigantismo. Mutantes para a produção de giberelina apresentaram fenótipo anão e esta mutação já foi revertida com a aplicação de ácido giberélico exógeno. A anatomia de plântulas cultivadas in vitro e ex vitro fornece informações que podem auxiliar na melhoria das técnicas de micropropagação e na sua seleção precoce. Objetivou-se verificar a diferenciação das estruturas anatômica entre plantas normais e variantes somaclonais. Para tal, utilizaram-se folhas de 'Prata-anã' cultivadas in vitro, em fase de aclimatização e no campo após a constatação da variação somaclonal. Secções paradérmicas foram realizadas para avaliação do complexo estomático. Seç̧ões transversais foram realizadas para medições da espessura das faces adaxial e abaxial da epiderme, medições dos parênquimas clorofilianos e da nervura central. Os resultados permitiram verificar diferenças estruturais das plantas ao longo das fases de cultivo. Foi possível também determinar marcadores anatômicos baseados no diâmetro da nervura central e na hipoderme inferior que permiti distinguir as plantas normais das variantes somaclonais.

Palavras-chave: Cultivo in vitro; Marcadores anatômicos; Variação fenotípica

ABSTRACT - (Gibberellic acid $\left(\mathrm{GA}_{3}\right)$ and anatomy of the leaf epidermises to detect somaclonal variants of the banana tree Musa sp. Colla cv. Prata-anã (Musaceae)) Micropropagation of Musa plants is applied on a wide scale in order to obtain plantlets with high sanitary quality. In vitro cultivation may lead to somaclonal variation that can cause harm the producers. Currently, differentiation of somaclonal variants is possible only in the field based on the exaggerated growth of the plants. Mutants for gibberellin production are dwarfed and this mutation is reverted by applying gibberellic acid. The anatomy of plants cultivated in vitro and ex vitro can give information to improve micropropagation techniques. The objective of this work was to differentiate normal plants from variant ones by anatomic structures. For this propose, leaves of banana plants 'Prata-anã' cultivated in vitro, during the acclimatization phase and in the field after the visual detection of somaclonal variation, were used. Paradermic sections were produced to evaluate the stomata complex. Transverse sections were done to measure adaxial and abaxial epidermal-face thickness, chlorophyll parenchyma andmidrib. Structural differences were detected in plants during developmental phases. Moreover, in this work it was possible to determine anatomical markers to distinguish normal from variant plants based on midrib diameter and inferior hypodermis.

Key words: in vitro culture; Anatomic markers; Phenotypic variation

\section{Introdução}

O Brasil é hoje o segundo maior produtor de bananas no mundo, superado apenas pela Índia (FAO, 2006), onde os cultivares 'Prata-anã' e 'Nanicão' estão entre os principais plantados no país.

A micropropagação a partir de ápices caulinares cultivados in vitro está sendo extensivamente utilizada em diversos países para produção de mudas de bananeira. Esta técnica garante a obtenção de mudas livres de pragas e doenças o que reduz a disseminação de patógenos (Damasco et al., 1996; Álvares \& Caldas, 2002). Porém, o cultivo in vitro pode levar a ocorrência de variação somaclonal que pode acarretar em prejuízos aos produtores (Santos \& Rodrigues, 2004).

A variação somaclonal é definida como um tipo de variação no fenótipo de plantas regeneradas por cultura de tecidos. Esta variação pode ser de origem genética ou epigenética, que dependendo da cultivar, pode levar a morfologia do tipo anã, gigante, variegada, folhas lanceoladas entre outras
(Sahijram et al., 2003). Em bananeira 'Prata-anã' (AAB) uma variação somaclonal freqüente é o crescimento exagerado das plantas, que é detectado somente após o plantio em campo. Tal anormalidade prejudica o desenvolvimento dos cachos e dos frutos. A dificuldade em detectar esta variação, antes do repasse destas para os agricultores, tem limitado a utilização da propagação em bananeiras (Sandoval et al., 1999; Albany et al., 2005).

As causas para as diversas variações somaclonais em bananeiras ainda parecem bastante incertas. Porém, sugerese que muitas dessas anomalias podem estar relacionadas a distúrbios no metabolismo das giberelinas. Sandoval et al. (1995) mostrou que variantes somaclonais para o gigantismo e nanismo responderam a aplicações exógenas de ácido giberélico $\left(\mathrm{GA}_{3}\right)$.

A anatomia vegetal tem sido adotada como ferramenta para o entendimento biológico de diversas espécies. Secções transversais de raiz, caule, folhas, entre outros órgãos, podem auxiliar na diferenciação ou mesmo diferenciar espécies

\footnotetext{
Parte da dissertação de Mestrado da primeira Autora

2 Universidade Federal de Lavras, Departamento de Biologia, Lavras, MG, Brasil

3 Universidade Federal de Lavras, Departamento de Química, Lavras, MG, Brasil

4 Autor para correspondência: emcastro@ufla.br
} 
dentro de um mesmo gênero podendo ser utilizada também para o entendimento fisiológico. Existem evidências de que a relação entre os diâmetros estomáticos polares e equatoriais é importante para determinar o momento de transferir bananeiras 'Prata-anã' do ambiente in vitro para o ex vitro (Rocha, 2005). Em outros estudos, a microscopia eletrônica permitiu detectar marcadores morfológicos para distinguir variantes somaclonais de plantas normais em 'Prata-anã' (Lacerda et al., 2008). Porém, esta técnica apresenta custo bastante elevado em sua aparelhagem.

Objetivou-se analisar alterações anatômicas foliares de bananeira 'Prata-anã' normais e variantes somaclonais durante o cultivo in vitro, aclimatização e após cinco meses de plantio, período em que se pode visualizar esse fenômeno.

\section{Material e métodos}

Material vegetal - O cultivo in vitro dos explantes de bananeira 'Prata Anã' foi realizado no Laboratório Central de Biologia Molecular e a aclimatização das mudas no Laboratório de Cultura de Tecidos de Plantas, ambos da Universidade Federal de Lavras, Lavras, MG.

Para o cultivo in vitro, explantes foram extraídos de plantas consideradas normais $(\mathrm{N})$ pelos padrões de desenvolvimento esperados para a cultivar e de plantas com variação somaclonal (V) identificadas pela característica do gigantismo. Estas matrizes encontravam-se em fase de produção no campo.

Os explantes provenientes de ápices caulinares de 'Prata Anã' variantes somaclonais e não-variantes foram cultivados em meio de cultura para multiplicação durante 30 dias e de enraizamento por mais 30 dias em sala de crescimento a $25 \pm 1^{\circ} \mathrm{C}$ e 16 horas de fotoperíodo, de acordo com os protocolos descritos por Lacerda et al. (2008), sendo o meio de multiplicação constituído por MS (Murashige \& Skoog, 1962) sais e vitaminas suplementado com $3 \%$ sacarose, $5 \mathrm{mg} \mathrm{L}^{-1}$ de BAP (6-benzilaminopurina), $5 \mathrm{~g}$ $\mathrm{L}^{-1}$ ágar, pH 5,7. O meio de enraizamento foi constituído por MS (Murashige $\&$ Skoog, 1962) sais e vitaminas suplementado com 3\% sacarose, $0,5 \mathrm{mg}$ $\mathrm{L}^{-1}$ de NAA (ácido naftalenoacético), $5 \mathrm{~g} \mathrm{~L}^{-1}$ ágar, $\mathrm{pH} 5,7$. Em seguida, as plantas foram aclimatizadas em sala de crescimento a $25 \pm 1^{\circ} \mathrm{C}$ e 12 horas de fotoperíodo, a $36 \mu \mathrm{mol} \cdot \mathrm{m}^{-2} \cdot \mathrm{s}^{-1}$ de irradiância por 60 dias, em tubetes com substrato PlantMax ${ }^{\circledR}$.

Foram coletadas folhas de número 2 (Rocha, 2005) de variantes somaclonais provenientes de três explantes distintos (variante 1,2 e 3 ) e de um não variante somaclonal nas seguintes fases de cultivo: 1) cultivo in vitro após o período de enraizamento, 2) após 60 dias de aclimatização, 3) em campo após a constatação da presença ou ausência de variação somaclonal de acordo com as características morfológicas descritas por Guimarães (2005).

Aplicação de ácido giberélico para verificar a presença de variantes somaclonais e possível ação fitotóxica de $\mathrm{GA}_{3}$ - No intuito de verificar o efeito de diferentes doses de ácido giberélico exógeno aplicado em bananeiras 'Prata-anã' normais e variantes somaclonais, assim como o efeito fitotóxico deste regulador de crescimento, foram utilizadas 100 mudas micropropagadas com aproximadamente dois meses de aclimatização sem o prévio conhecimento de quais mudas apresentavam ou não variação somaclonal. Estas plantas foram cultivadas de acordo com o material vegetal descrito acima.

Foram determinados cinco tratamentos para avaliar a dose resposta e a indução de fitotoxidez, sendo o primeiro tratamento o controle com água destilada e os demais tratamentos com as concentrações de $10 \mathrm{mg} \mathrm{L}^{-1}$, $20 \mathrm{mg} \mathrm{L}^{-1}, 40 \mathrm{mg} \mathrm{L}^{-1}$ e $80 \mathrm{mg} \mathrm{L}^{-1}$ de $\mathrm{GA}_{3}$ da Invitrogen ${ }^{\circledR}$. Com o auxílio de um borrifador manual foi aplicado $250 \mathrm{~mL}$ das soluções correspondentes a cada tratamento nos tempos 0,20 e 40 dias.

$\mathrm{O}$ experimento foi conduzido em DBC (delineamentos blocos casualizados), em parcelas subdivididas no tempo, sendo que cada um dos tratamentos possuía quatro plantas por repetição e cinco repetições que correspondiam aos blocos totalizando 20 mudas por tratamento. As mudas foram mantidas em estufa, em cinco bandejas de 24 células contendo substrato Plantmax ${ }^{\circledR}$. As médias foram comparadas pelo teste Tukey com $5 \%$ de probabilidade de erro, no programa SISVAR (Ferreira, 2000).
O parâmetro utilizado para medição da altura da folha foi tomado como a medida da base da planta até o ápice da bainha da folha de número 1 (Rocha, 2005). Foram analisados nos tempos 0, 20 e 40 dias a altura de cada planta.

Anatomia vegetal - Foram coletadas folhas de número 2 (Rocha, 2005) de variantes somaclonais provenientes de três plantas distintas (variante 1,2 e 3) e de uma planta normal nas seguintes fases de cultivo: 1) cultivo in vitro após o período de enraizamento; 2) após 60 dias de aclimatização; 3) em campo após a constatação da presença ou ausência de variação somaclonal de acordo com as características morfológicas descritas por Guimarães (2005).

As folhas coletadas foram fixadas em FAA 70\% (Johansen, 1940) por 72 horas e posteriormente conservadas em álcool $70^{\circ} \mathrm{GL}$. Secções transversais foram realizados na região mediana da folha com o auxílio do micrótomo manual. Em seguida, as secções foram clarificadas em solução de hipoclorito de sódio $1,5 \%$. Em seguida foram lavadas em água destilada e submetidas a coloração com azul de astra e safranina (Kraus \& Arduin, 1997). As lâminas semi-permanentes foram montadas em glicerina 50\% (Strasburger, 1924). Para a avaliação da densidade estomática (número de estômatos por $\mathrm{mm}^{2}$ ) realizaram-se secções paradérmicas na face abaxial da epiderme, visto que a face adaxial apresenta um número bastante reduzido de estômatos (Lacerda et al., 2008) não sendo realizadas neste trabalho. Nas fases de cultivo in vitro e aclimatização foram analisadas cinco folhas de plantas normais e cinco folhas de cada um dos três variantes somaclonais. Na fase de campo foram analisadas cinco folhas provenientes de cinco diferentes bananeiras com variação somaclonal e cinco diferentes bananeiras normais. As secções transversais foram utilizadas para mensuração da espessura dos tecidos clorofilianos, da nervura central e das faces abaxial e adaxial da epiderme. Nas secções transversais das folhas dos indivíduos de todos os tratamentos foram analisados: espessura da epiderme nas faces abaxial e adaxial, parênquimas paliçádico e esponjoso, hipodermes superior e inferior e diâmetro da nervura central (Kraus \& Arduin, 1997), sendo que a nervura central das folhas em campo não foi avaliada. Foram avaliados quatro campos em lâminas diferentes de cinco folhas no terço médio foliar.

Os parâmetros avaliados nas secções paradérmicas em cada tratamento foram: densidade estomática, diâmetros estomáticos polar e equatorial. Sendo determinadas através da contagem dos estômatos (densidade estomática) situados numa área de um $\mathrm{mm}^{2}$ e demais parâmetros de acordo com Boeger \& Wiscniewski (2003) utilizando-se 24 campos, quatro por condição de cultivo, na face adaxial da folha.

$\mathrm{O}$ delineamento experimental inteiramente casualisado foi utilizado com dois tratamentos (variantes e normais, e a repetição composta por três explantes variantes) para cada uma das três fases de cultivo e cinco plantas para cada tratamento. O esquema experimental foi o fatorial de $2 \times 2$. As médias foram comparadas pelo teste Tukey com $5 \%$ de probabilidade de erro no programa SISVAR (Ferreira, 2000).

\section{Resultados}

$\mathrm{Na}$ aplicação de diferentes doses de ácido giberélico para verificar a ação dessas doses e a possível ocorrência de fitotoxidez em função da presença do regulador, não foi observada com a aplicação de variadas concentrações de $\mathrm{GA}_{3}$ em mudas de 'Prata-anã' micropropagadas, diferença significativa de crescimento entre os tratamentos, ao nível de 5\% pelo teste de $\mathrm{F}$ após os 40 dias de avaliação da altura das mudas. No entanto, as alturas das plantas modificaram-se de acordo com o passar dos dias, mostrando o crescimento padrão das mudas como esperado. Tal comportamento de crescimento é linear, com um ajuste de 99,97\%, como observado no gráfico da análise de regressão (Fig. 1).

De acordo com os resultados obtidos não foi possível distinguir os variantes dos não variantes somaclonais com a aplicação das soluções a base de ácido giberélico $\left(\mathrm{GA}_{3}\right) \mathrm{e}$ 
água destilada. As diferentes doses utilizadas não apresentaram efeito de fitotoxidez nas plantas tratadas.

Nos resultados obtidos nas secções paradérmicas dos materiais coletados em diferentes fases de cultivo, somente o diâmetro polar dos estômatos na fase de campo apresentou diferença significativa ao nível de $5 \%$ pelo teste de $\mathrm{F}$ nas bananeiras 'Prata-anã' em relação às plantas nas outras fases de cultivo (Tab. 1). Na fase in vitro e de aclimatização, tanto as plantas normais quanto as variantes apresentaram diâmetro estomático polar maior que as plantas em campo. Além disso, pode-se verificar que a densidade estomática das plantas normais e variantes somaclonais aumenta ao longo das fases de desenvolvimento in vitro, de aclimatização e em campo (Tab. 1). O diâmetro equatorial não apresentou diferenças significativas ao longo das fases de cultivo (Tab. 1). De acordo com as Figs. 2-7, também é possível observar que os estômatos, tanto das plantas normais como variantes, apresentam-se mais elípticos na fase de cultivo in vitro e na fase de aclimatização em relação à fase de campo.

Nas secções transversais pode-se observar que a epiderme, nas faces adaxial e abaxial, apresentou diminuição da espessura ao longo do desenvolvimento das plantas (Tab. 2). O parênquima paliçádico apresentou um crescimento ao passar do ambiente in vitro para a aclimatização, assim como do transplante para o campo. Já o parênquima esponjoso apresentou média de tamanho igual nas fases in vitro e aclimatizadas. No entanto, na fase de cultivo em campo o parênquima esponjoso apresentou, em média, maior espessura em relação às demais fases de cultivo.

A nervura central das plantas normais apresentou aumento no diâmetro quando as plantas foram transplantadas para o ambiente externo. E, o contrário, ocorreu para as variantes. Pode-se observar também que a nervura central das plantas normais em fase de aclimatização é maior que a nervura das variantes na mesma fase. Já a hipoderme superior não apresentou tendência de diferenciação ao longo do desenvolvimento da planta. A hipoderme inferior apresentou diminuição na passagem das plantas para o campo. Na fase in vitro a hipoderme inferior das plantas normais é maior que a das plantas variantes, já na fase de aclimatização é possível verificar um padrão de crescimento deste tecido nas plantas variantes em relação as normais. Neste caso, pode se observar que na passagem da fase in vitro para a de aclimatização, a hipoderme inferior das plantas normais não aumentou em tamanho, já a das plantas variantes houve crescimento significativo (Tab. 2).
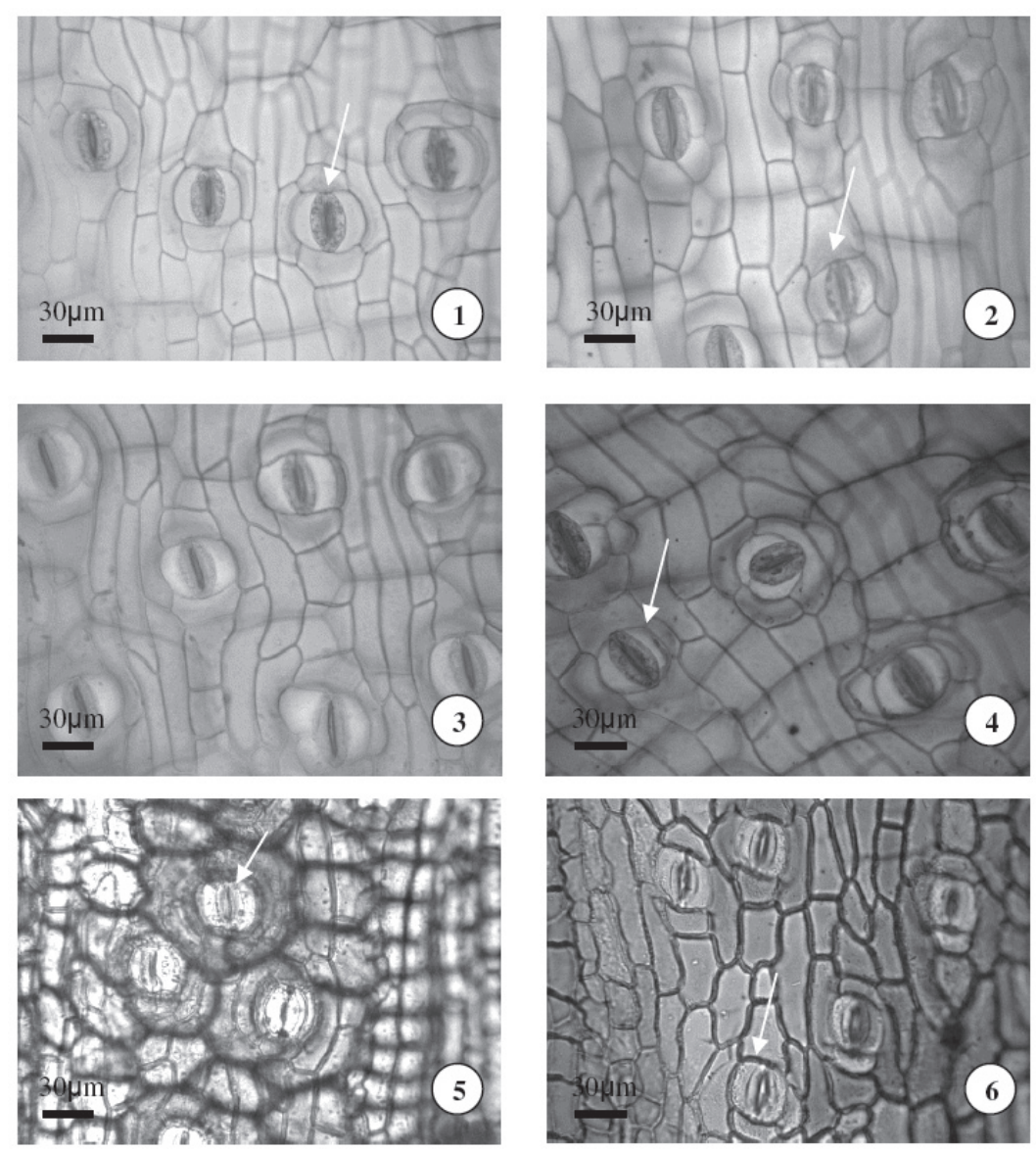

Figura 1-6. Secções paradérmicas de folhas de bananeira 'Prata-anã' (40 ZM). 1 - plantas normais in vitro; 2 - plantas normais aclimatadas; 3 - plantas variantes somaclonais in vitro; 4 - plantas variantes somaclonais aclimatadas; 5 - plantas normais em campo; 6 - plantas variantes somaclonais em campo. As setas indicam complexos estomáticos em cada uma das secções. 
Tabela 1. Médias dos diâmetros equatorial e polar $(\mu \mathrm{m})$ e da densidade estomática de folhas de bananeira 'Prata-anã' normais (N) e variantes somaclonais (V) durante o cultivo in vitro, aclimatadas e em campo.

\begin{tabular}{|c|c|c|c|}
\hline Planta & Diâmetro Equatorial & $\begin{array}{c}\text { Diâmetro } \\
\text { Polar }\end{array}$ & Densidade Estomática \\
\hline $\mathrm{N}$ in vitro & $17,42^{\mathrm{b}}$ & $33,06^{\mathrm{b}}$ & $92,45^{\mathrm{a}}$ \\
\hline $\mathrm{V}$ in vitro & $17,23^{\mathrm{ab}}$ & $33,25^{\mathrm{b}}$ & $94,80^{\mathrm{a}}$ \\
\hline $\mathrm{N}$ aclimatada & $17,93^{\mathrm{b}}$ & $32,45^{\mathrm{b}}$ & $135,05^{b}$ \\
\hline V aclimatada & $18,25^{\mathrm{b}}$ & $32,69^{\mathrm{b}}$ & $136,30^{\mathrm{b}}$ \\
\hline N campo & $17,19^{\mathrm{a} b}$ & $27,80^{\mathrm{a}}$ & $243,00^{c}$ \\
\hline V campo & $15,41^{\mathrm{a}}$ & $25,92^{\mathrm{a}}$ & $221,52^{\mathrm{c}}$ \\
\hline
\end{tabular}

${ }^{a}$ Valores com sobrescritos diferentes em uma mesma coluna diferem entre si, pelo Teste Tukey $(\mathrm{P}<0,05)$.

Tabela 2. Valores médios ( $\mu \mathrm{m})$ da epiderme abaxial (E.Ab), parênquima paliçádico (P.Pç), hipoderme superior (Hipo Sup), parênquima esponjoso (P.Ep.), hipoderme inferior (Hipo Inf), epiderme adaxial (E.Ad) e da nervura central (N.C) das folhas de bananeira 'Prata-anã' normais (N) e variantes somaclonais (V) durante o cultivo in vitro, aclimatadas e em campo. Os traços (-) indicam que não foram medidas estas estruturas

\begin{tabular}{|c|c|c|c|c|c|c|c|}
\hline Planta & E. Ab. & E. Ad & P. Pç & Hipo Sup & P. Ep & Hipo Inf & N. C \\
\hline $\mathrm{N}$ in vitro & $20,93^{\mathrm{c}}$ & $22,23^{\mathrm{d}}$ & $62,37^{\mathrm{ab}}$ & $70,89^{a}$ & $76,74^{\mathrm{a}}$ & $53,49^{\mathrm{c}}$ & $536,15^{\text {ab }}$ \\
\hline $\mathrm{V}$ in vitro & $18,18^{\mathrm{bc}}$ & $19,99^{\mathrm{cd}}$ & $52,48^{\mathrm{a}}$ & $68,40^{\mathrm{a}}$ & $64,08^{\mathrm{a}}$ & $45,23^{\mathrm{b}}$ & $557,28^{\mathrm{b}}$ \\
\hline $\mathrm{N}$ aclimatada & $15,45^{\mathrm{b}}$ & $19,43^{\mathrm{bc}}$ & $64,31^{\mathrm{ab}}$ & $65,63^{\mathrm{a}}$ & $100,13^{\mathrm{a}}$ & $53,44^{\mathrm{c}}$ & $627,43^{\mathrm{c}}$ \\
\hline V aclimatada & $15,78^{\mathrm{b}}$ & $18,21^{\mathrm{abc}}$ & $75,43^{\mathrm{b}}$ & $71,43^{\mathrm{a}}$ & $96,13^{\mathrm{a}}$ & $62,74^{\mathrm{d}}$ & $482,38^{\mathrm{a}}$ \\
\hline $\mathrm{N}$ campo & $10,69^{\mathrm{a}}$ & $16,50^{\mathrm{a}}$ & $206,91^{\mathrm{c}}$ & $60,18^{\mathrm{a}}$ & $467,87^{\mathrm{b}}$ & $20,01^{\mathrm{a}}$ & - \\
\hline V campo & $11,46^{\mathrm{a}}$ & $17,11^{\mathrm{ab}}$ & $198,26^{\mathrm{c}}$ & $72,56^{\mathrm{a}}$ & $479,62^{b}$ & $18,78^{\mathrm{a}}$ & - \\
\hline
\end{tabular}

${ }^{a}$ Valores com sobrescritos diferentes em uma mesma coluna diferem entre si, pelo Teste Tukey $(\mathrm{P}<0,05)$.

\section{Discussão}

De acordo com os resultados do experimento de aplicação de ácido giberélico, possivelmente não existiam variantes em meio a população de plantas analisadas. No entanto, acreditamos que a solução não apresentou os fatores necessários para sua ação já que de acordo com Alcázar et al. (2005) a presença de Tween 20, que é um detergente biológico, seria necessária para aplicação de $\mathrm{GA}_{3}$ e visualização dos efeitos deste regulador de crescimento. O Tween 20 é um detergente biológico que pode auxiliar na penetração do ácido giberélico $\left(\mathrm{GA}_{3}\right)$ por quebrar a barreira de cera presente na estrutura foliar. Assim, provavelmente, estas plantas não apresentaram diferenciação de crescimento devido provavelmente à espessa camada de cera presente nas mudas de 'Prata-anã' (Lacerda et al., 2008).

Os resultados obtidos neste trabalho permitiram verificar modificações na estrutura anatômica de bananeira 'Prata-anã' entre as fases de cultivo in vitro, aclimatização e em campo e entre as bananeiras normais e variantes.

A resposta na diminuição do diâmetro polar e o aumento da densidade estomática das plantas transplantadas para o campo tanto nas plantas normais como nas variantes somaclonais (Tab. 1), pode estar associada à economia de água no ambiente ex vitro, já que folhas com estômatos menores apresentam maior eficiência de uso da água e a diferença no tamanho da abertura estomática apresenta maior efeito sobre a difusão de água do que sobre a difusão de $\mathrm{CO}_{2}$ (Bidwell, 1964). Este efeito pode estar acentuado nas variantes pelo fato de apresentarem estatura bastante elevada em relação as normais, fato este que pode levar a um aumento na taxa de transpiração e maior demanda de água. A ocorrência de menor densidade estomática e maior diâmetro polar em bananeiras cultivadas in vitro e em aclimatização em relação às plantas em campo, pode indicar um mecanismo de eficiência na abertura e fechamento dos estômatos e perda de água para evitar a dessecação das plantas. Além disso, a presença de estruturas estomáticas mais elípticas na fase de cultivo in vitro e aclimatização indica que estas estruturas são menos funcionais em relação às mesmas estruturas na fase de campo, na qual apresentamse mais arredondadas. Este fato pode estar relacionado à elevada umidade relativa do ar presente nas condições in vitro e, dessa maneira, os estômatos têm pouca funcionalidade nestas condições. O mesmo ocorre em abacaxizeiros micropropagados quando estes são passados para a fase de aclimatização (Silva, 2006). No entanto, o aumento na densidade e no tamanho dos estômatos foi relatado como fator para a excessiva perda de água após o transplante do ambiente in vitro para o ex vitro (Lee et al., 1988; Sciutti \& Morini, 1995). Em diversas espécies, a densidade estomática decresce após o transplante dos explantes in vitro para o ambiente ex vitro, entretanto, para outras espécies a densidade estomática pode sofrer um incremento após este 
transplante (Johanson et al., 1992; Noé \& Bonini, 1996; Tichá et al., 1999; Brutti et al., 2002).

Ao contrário das folhas de abacaxizeiro micropropagado, em que o transplante das plantas do ambiente in vitro para o ex vitro levou a um aumento da epiderme adaxial (Silva, 2006), em 'Prata-anã' houve uma diminuição das epidermes ao longo das fases de desenvolvimento. Isto pode ter ocorrido em função de uma maior disponibilidade de luminosidade, estimulando o desenvolvimento do parênquima clorofiliano (Tab. 2). O parênquima esponjoso, porém, apresentou aumento somente após o transplante das plantas in vitro para a aclimatização (Tab. 2). Estes tecidos são responsáveis pela fotossíntese e, provavelmente, apresentaram um maior desempenho de crescimento devido ao aumento da capacidade fotossintética da planta (Araus et al., 1986).

Os fatores ambientais, como temperatura e umidade, afetam as dimensões e o arranjo dos elementos vasculares para garantir um aumento do transporte dos assimilados quando a planta está sujeita a algum tipo de estresse (Baas \& Schweingruber, 1987; Alves \& Angyalossy-Alfonso, 2000) como, por exemplo, a passagem do cultivo in vitro para o ambiente externo. Estes fatores podem estar relacionados ao aumento da nervura central nas plantas normais durante a transferência do cultivo in vitro para o ex vitro. Além disso, foi possível diferenciar as plantas normais das variantes somaclonais com base no diâmetro da nervura central na fase de aclimatização dessas plantas. Este dado pode ser utilizado como marcador morfológico para detectar precocemente os variantes antes que eles sejam levados para o campo. Um outro marcador morfológico que pôde ser estabelecido neste trabalho foi a diferença na espessura da hipoderme inferior entre as variantes e as normais tanto nas fases de aclimatização como in vitro. Neste caso, foi verificado que este tecido cresce em espessura nas plantas variantes ao transplantá-las do ambiente in vitro para ex vitro.

De acordo com Costa (2008) verificou que plantas de bananeiras provenientes da fase de enraizamento in vitro, em ambiente mixotrófico, apresentaram reduzido controle sobre a perda de água e alta densidade estomática. A reduzida transpiração das folhas formadas na fase de aclimatização pode ser atribuída ao menor número de estômatos por unidade de área foliar, à maior capacidade destes em restringir a perda de água e à presença da cera epicuticular.

Desta maneira, as análises da estrutura anatômica de bananeiras 'Prata-anã' micropropagadas representam uma importante ferramenta para distinguir plantas normais e variantes somaclonais, além de permitir observar modificações estruturais ao longo das fases de desenvolvimento dessas plantas. Este estudo permitiu também relacionar as modificações anatômicas das plantas com diversos processos fisiológicos para a compreensão dos fatores que levam à variação somaclonal. Nesse sentido, análises mais aprofundadas são necessários para melhor compreensão da variação somaclonal em bananeiras 'Prata-anã'.
O presente estudo demonstrou que a aplicação foliar de ácido giberélico não permitiu distinguir os variantes somaclonais dos normais.

A espessura da hipoderme inferior constitui-se em um eficiente marcador morfológico para detecção precoce de variantes somaclonais de bananeiras 'Prata-anã'. Foi possível diferenciar as plantas normais das variantes somaclonais com base no diâmetro da nervura central na fase de aclimatização dessas plantas.

Essas variações marcantes nas estruturas anatômicas ao longo das fases de cultivo de 'Prata-anã' micropropagada, representam respostas às mudanças ambientais que estas plantas sofreram ao longo do seu desenvolvimento. Dessa forma, determinou-se marcadores morfológicos que permitiram distinguir precocemente as plantas normais das variantes somaclonais.

\section{Referências bibliográficas}

ALCÁZAR, R.; GARCÍA-MARTÍNEZ, J.L.; CUEVAS, J.C.; TIBURCIO, A.F. \& ALTABELLA, T. 2005. Overexpression of ADC2 in Arabidopsis induces dwarfism and late-flowering through GA deficiency. The Plant Journal 43: 425-436.

ÁLVARES, M.C. \& CALDAS, L.S. 2002. Crescimento, produção e variação somaclonal em bananeiras micropropagadas. Pesquisa Agropecuária Brasileira 37(3): 415-420.

ALVES, E.S. \& ANGYALOSSY-ALFONSO, V. 2000. Ecological trends in the wood of some Brazilian species 1: growth rings and vessels. IAWA Journal 21: 3-30.

ALBANY, N.R.; VILCHEZ, A.J.; LEYANIS GARCIA, L. \& JIMÉNEZ, E. 2005. Comparative study of morphological parameters of Grand Naine banana (Musa AAA) after in vitro multiplication with growth retardants. Plant Cell, Tissue and Organ Culture 83: 357-361.

ARAUS, J.L.; ALEGRE, L.; TAPIA, L.; CALAFELL, R. \& SERRET, M.D. 1986. Relationship between photosynthetic capacity and leaf struture in several shade plants. American Journal of Botany 73(12): 1760-1770.

BAAS, P. \& SCHWEINGRUBER, F.H. 1987. Ecological trends in the wood anatomy of trees, shrubs and climbers from Europe. IAWA Bulletin 8: 245-274.

BIDWELL, R.G.S. 1964. Protein synthesis and turn over in cultured plant tissue: sources of carbon synthesis and the fate of the protein breakdown products. Nature 203: 367-373.

BOEGER, M.R. \& WISNIEWSKI, C. 2003. Comparação da morfologia foliar de espécies arbóreas de três estádios sucessionais distintos de floresta ombrófila densa (Floresta Atlântica) no Sul do Brasil. Revista Brasileira de Botânica 26(1): 61-72.

BRUTTI, C.B.; RUBIO, E.J.; LLORENTE, B.E. \& APÓSTOLO, N.M. 2002. Artichoke leaf morphology and surface features in different micropropagation stages. Biologia Plantarum 45(2): 197-204.

COSTA, F.H. da S. 2007. Micropropagação da bananeira: características fitotécnicas, fisiológicas e anatômicas. 113p. Dissertação (Mestrado em Agronomia/Fitotecnia) - Universidade Federal de Lavras, Lavras, MG.

DAMASCO, O.P.; GODWIN, I.D.; SMITH, M.K. \& ADKINS, S.W. 1996. Gibberellic acid detection of dwarf off-types in micropropagated Cavendish bananas. Australian Journal of Experimental Agriculture 36(2): 237-241.

FAO. 2006. FAO statistical databases: major food and agricultural commodities and producers: Countries by commodity: Selected commodity: bananas. Disponível em: <http://www.fao.org/es/ess/top/ commodity>. Acesso em: 9 set. 2006.

FERREIRA, D.F. 2000. Análises estatísticas por meio do Sisvar para Windows: versão 4.0. In: REUNIÃO ANUAL DA REGIÃO BRASILEIRA DA SOCIEDADE INTERNACIONAL DE BIOMETRIA, 45., São Carlos. Anais... São Carlos, UFSCar. p.255-258.

GUIMARÃES, N.C.C. 2005. Identificação de variantes somaclonais em bananeiras Prata-anã, utilizando técnicas moleculares e citogenéticas. 50 f. Dissertação (Mestrado em Agroquímica/ Agrobioquímica) - Universidade Federal de Lavras, Lavras, MG. 
KRAUS, J.E. \& ARDUIN, M. 1997 Manual básico de métodos em morfologia vegetal. Seropédica, UFRRJ.

LACERDA, G.A.; SILVA, J.O.C.; ABREU, J.C.; ALVES, E. \& PAIVA, L.V. 2008. Características morfoanatômicas da epiderme foliar de plantas variantes e não variantes somaclonais de bananeiras (Musa sp. Colla cv. Prata-anã) cultivadas in vitro. Acta Botanica Brasilica 22(1): 85-90.

LEE, N.; WEZSTEIN, Y. \& SOMMER, H.E. 1988. Quantum flux density effects on the anatomy and surface morphology of in vitro - and in vivo-developed Sweetgum leaves. The Journal of American Society for Horticultural Science 113(1): 167-171.

MURASHIGE, T. \& SKOOG, F. 1962. A revised medium for rapid growth and bioassays with tobacco tissue cultures. Physiologia Plantarum 15(6): 473-479.

JOHANSEN, D.A. 1940. Plant microtechnique. New York, Mc Graw-Hill. JOHANSON, M.; KRONESTEDT-ROBARDS, E.C. \& ROBARDS, A.W. 1992. Rose leaf structure in relation to different stages of micropropagation. Protoplasma 166: 165-176.

NOÉ, N. \& BONINI, L. 1996. Leaf anatomy of highbush blueberry grown in vitro and during acclimatization to ex vitro conditions. Biologia Plantarum 38: 19-25.

ROCHA, H.S. 2005. Luz e sacarose na micropropagação da bananeira 'Prata-anã': alterações morfoanatômicas. 98 f. Dissertação (Mestrado em Fitotecnia) - Curso de Pós-graduação em Agronomia, Universidade Federal de Lavras, Lavras, MG.
SAHIJRAM, L.; SONEJI, J.R. \& BOLLAMMA, K.T. 2003. Invited review: analyzing somaclonal variation in micropropagated bananas (Musa spp.). In vitro Cellular \& Developmental Biology - Plant 39: 551-556.

SANDOVAL, J.; KERBELLEC, F.; CÔTE, F. \& DOUMAS, P. 1995. Distribution of endogenous gibberellins in dwarf and giant off-types banana (Musa AAA, cv. 'Grand nain') plants from in vitro propagation. Plant Growth Regulation 17: 219-224.

SANDOVAL, J.A.; CÔTE, F. \& DOUMAS, P. 1999. Reconocimiento in vitro de variantes somaclonales de porte alto en banano (cv. 'Gran enano' Musa AAA). Respuesta a un tratamiento con $\mathrm{GA}_{3}$. Corbana 24(51): 11-20.

SANTOS, C.C.C. \& RODRIGUES, P.H.V. 2004. Variação somaclonal em mudas micropropagadas de bananeira, cultivar Pacovan. Bragantia 63(2): 201-205.

SCIUTTI, R. \& MORINI, S. 1995. Water loss and photosynthesis of plum plantlets by relative humidty during rooting in vitro. Journal of Horticultural Science 70(2): 221-228.

SILVA, A.B. 2006. Biorreatores e luz natural na micropropagação do abacaxizeiro. $132 \mathrm{f}$. Tese (Doutorado em Fitotecnia) - Universidade Federal de Lavras, Lavras, MG.

STRASBURGER, E. 1924. Handbook of practical botany for the botanical laboratory and private student. $8^{\text {th }}$ ed. London, George Allen \& Unwin, Ltd.

TICHÁ, I.; RADOCHOVÁ, B. \& KADLECEK, P. 1999. Stomatal morphology during acclimatization of tabacco plantlets to ex vitro conditions. Biologia Plantarum 42(3): 469-474. 